\title{
ANALYSIS OF SUSPECTED HYBRID SWARMS IN THE GENUS EUCALYPTUS
}

\author{
H. T. CLIFFORD \\ Botany School, University of Melbourne
}

Received 4.vi.53

\section{INTRODUCTION}

FoR arborescent species with long periods between successive generations and flowers borne on slender branches at great height, it is desirable to develop indirect methods for the study of cross breeding. Such a problem arises frequently in the Australian genus Eucalyptus, for which hybrid swarns have often been reported (Brett, 1938; Pryor, 1950). The following method of analysing such swarms differs from most of those previously described (Anderson, 1949) in that it requires a knowledge of the variability of the progeny of individual members of the hybrid swarm rather than a knowledge of the variability of the swarm itself.

\section{EXPERIMENTAL MATERIAL}

The two tree species, $E$. elaeophora F. Muell. and $E$. goniocalyx F. Muell. have been regarded as closely related by some (Bentham, I866) and by others as belonging to different sections of the genus (Baker and Smith, I920; Blakeley, 1934). They are not difficu: to distinguish, but at several localities in Victoria they are linkeci by a series of intermediate forms. The relationship between the two species has been investigated by raising seedlings from selected parent trees and measuring their juvenile characteristics, also by study of the field distribution of the species and their suspected hybrids.

The species names are here accepted and used in the sense in which they are defined in the Flora of Victoria (Ewart, 1930), although a study of the type material of each would suggest that the name $E$. elaeophora should be suppressed in favour of $E$. goniocalyx and that the plant generally known as $E$. goniocalyx ought to be redescribed under another name. However, in Australia there exists no confusion as to which species is meant when the current names are used and the author (like Maiden, 1914) does not propose that they should be changed.

\section{(o) Description of species}

Eucalyptus goniocalyx is a large tree which may attain a height of up to 200 feet with a diameter of 6-8 feet at breast height. The bark 
is smooth, except at the base of the trunk where it may be rough and flaky for several feet. Although usually grey it is sometimes strongly mottled with yellow. Its typical habitat is a well-drained soil, usually on hillsides in areas receiving an annual rainfall of 40-50 inches. Such conditions are common on the seaward slopes of the Eastern Highlands and here $E$. goniocalyx is often a co-dominant of the forest.

Eucalyptus elaeophora, on the other hand, is a small tree seldom growing to more than 80 feet, with a diameter of about 2 feet. It has a rough fiaky bark on all but the smallest branches. The usual habitat is on well-drained hillsides in places receiving an annual rainfall of about 18-30 inches. Except for a few localities in South

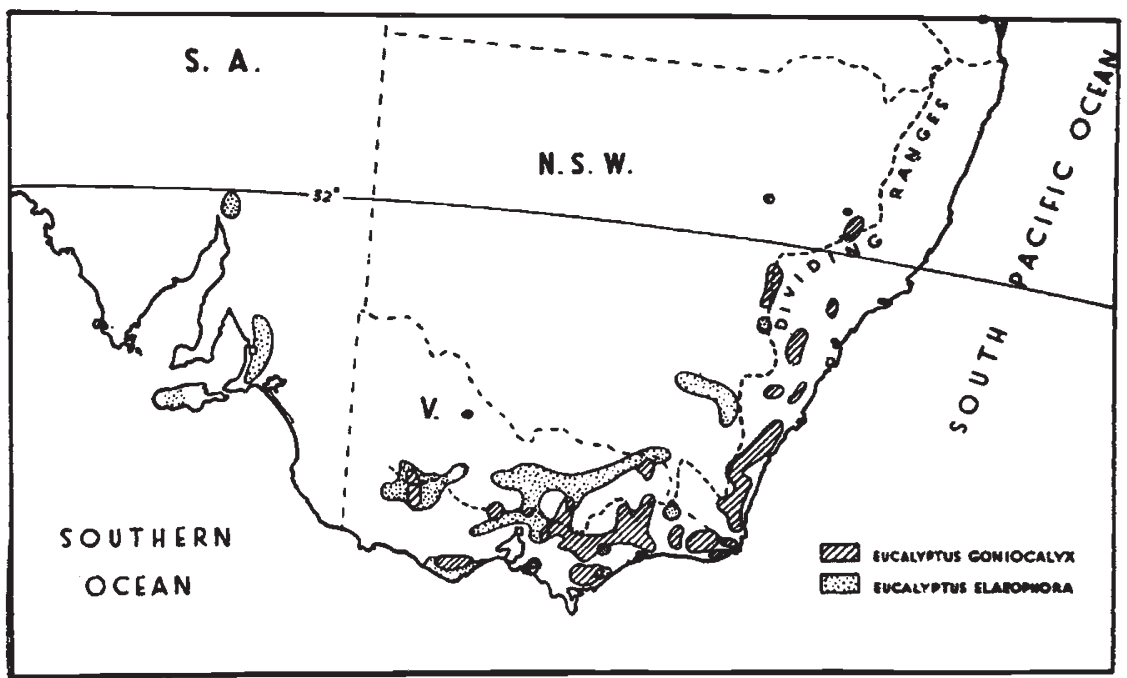

Fig. 1.-The distribution of Eucalyptus elaeophora and Eucalyptus goniocalyx. (Data in part from Carter, 1945.)

Australia and Southern Victoria, the species is confined to the inland slopes of the Eastern Highlands, fig. I.

The species differ in several other respects, the most important of which are illustrated in fig. 2.

\section{(b) Field studies}

In the course of mapping the distribution of the Eucalyptus species in the region of the Dandenong Range, Victoria, it was observed that $E$. elaeophora and $E$. goniocalyx graded into each other. So complete was this gradation that it was impossible to define accurately the boundary between the species (Clifford, 1953). Investigation of other areas showed that such intergrading was common where the habitats of the two species adjoined (fig. 3). Intermediate trees have been observed on the Dandenong Range, in several places on the hills about the Kinglake Plateau, and further east on the Cathedral 
Range. They are also reported to occur in the Grampian Ranges (L. D. Pryor in litt.).

In zones of intergradation the intermediate trees were variable
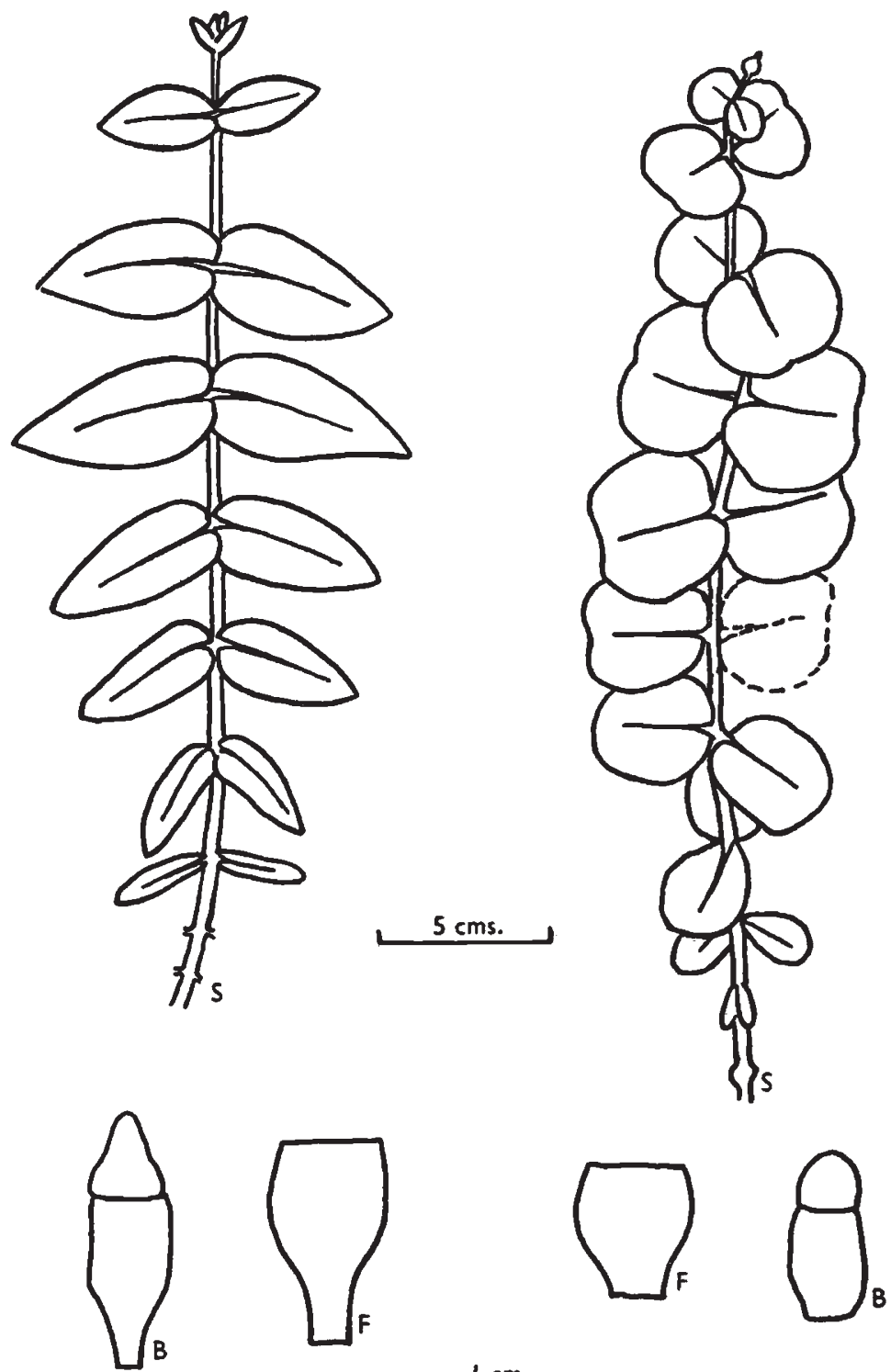

Eucalyptus Goniocalyx

Eucalyptus Eloeophoro

Frg. 2.-Some characteristic features of Eucalyptus elaeophora and Eucalyptus goniocalyx. S. seedling ; B. bud ; F. fruit.

inter se, some had a habit and bark suggesting an affinity with $E$. elaeophora, others had an appearance suggesting relationship with E. goniocalyx. The leaves on seedlings and on coppice shoots arising 
from the stools of felled trees in these zones were also very variable in shape. In stands of either E. elaeophora or E. goniocalyx there was little variability of the coppice foliage between different trees, or in the shape of the seedling leaves.

No transplant experiments have been attempted, but each species

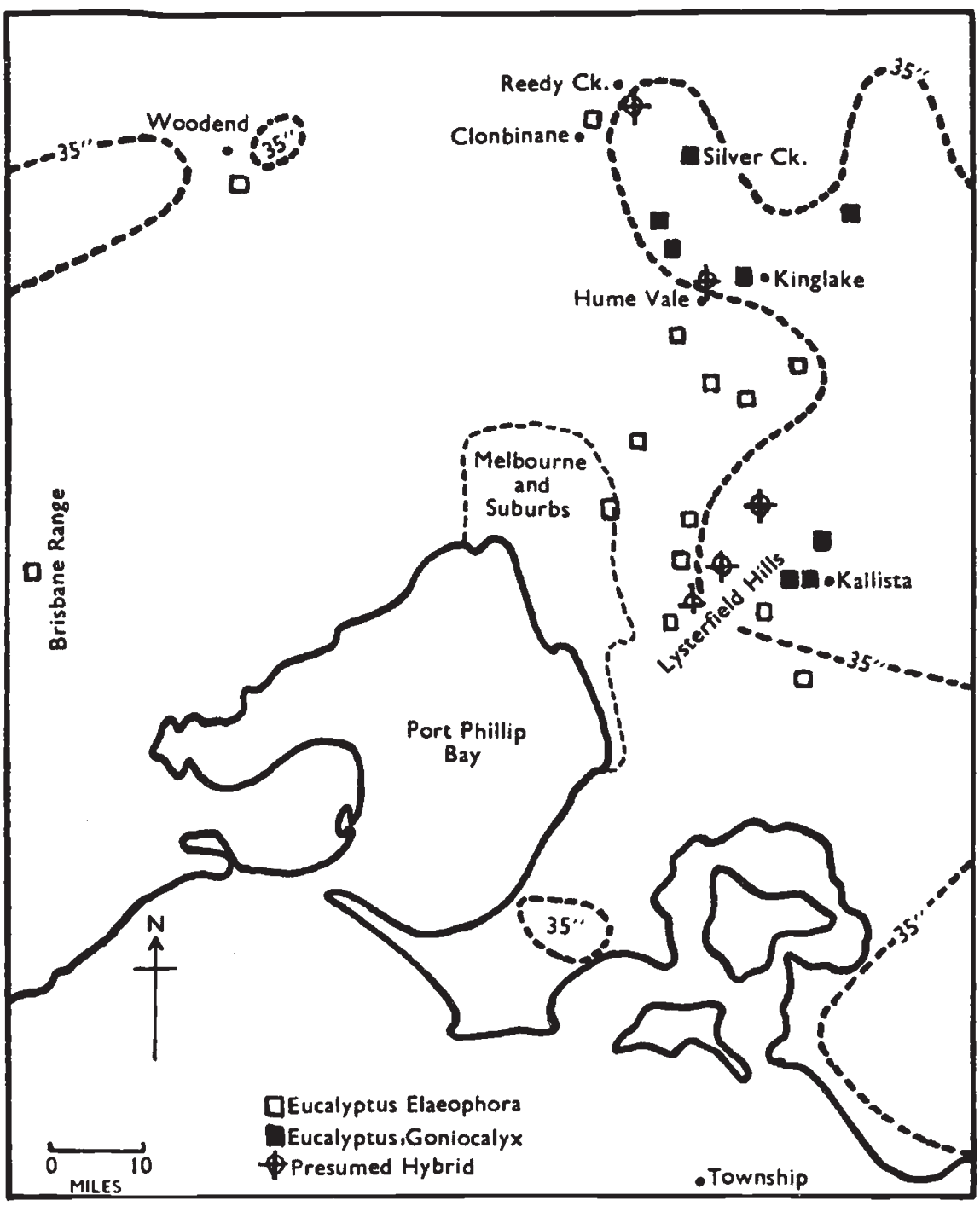

Fig. 3.-The distribution of Eucalyptus elaeophora, Eucalyptus goniocalyx and forms intermediate between them, in some localities near Melbourne.

has been observed growing in a variety of habitats. In each instance the species has retained its identity, even when grown in the habitat of the other, which confirms that they are not merely environmental forms of the one genotype. 
(c) Progeny studies

The seedling leaves of $E$. elaeophora and $E$. goniocalyx are very different in shape, and a comparison of these and the seedling leaves of the "intermediate" trees was undertaken. Seeds were collected from several trees typical of either one or the other species and also from trees that were intermediate between them. The seeds were sown in 8 in. pots filled with a friable red-loam and placed in a heated glasshouse. Approximately 30 seeds were sown in each pot and within a fortnight most of these had germinated. When the seedlings had grown about 2 pairs of leaves the number of plants per pot was reduced to twelve. The thinning was designed to leave these twelve plants

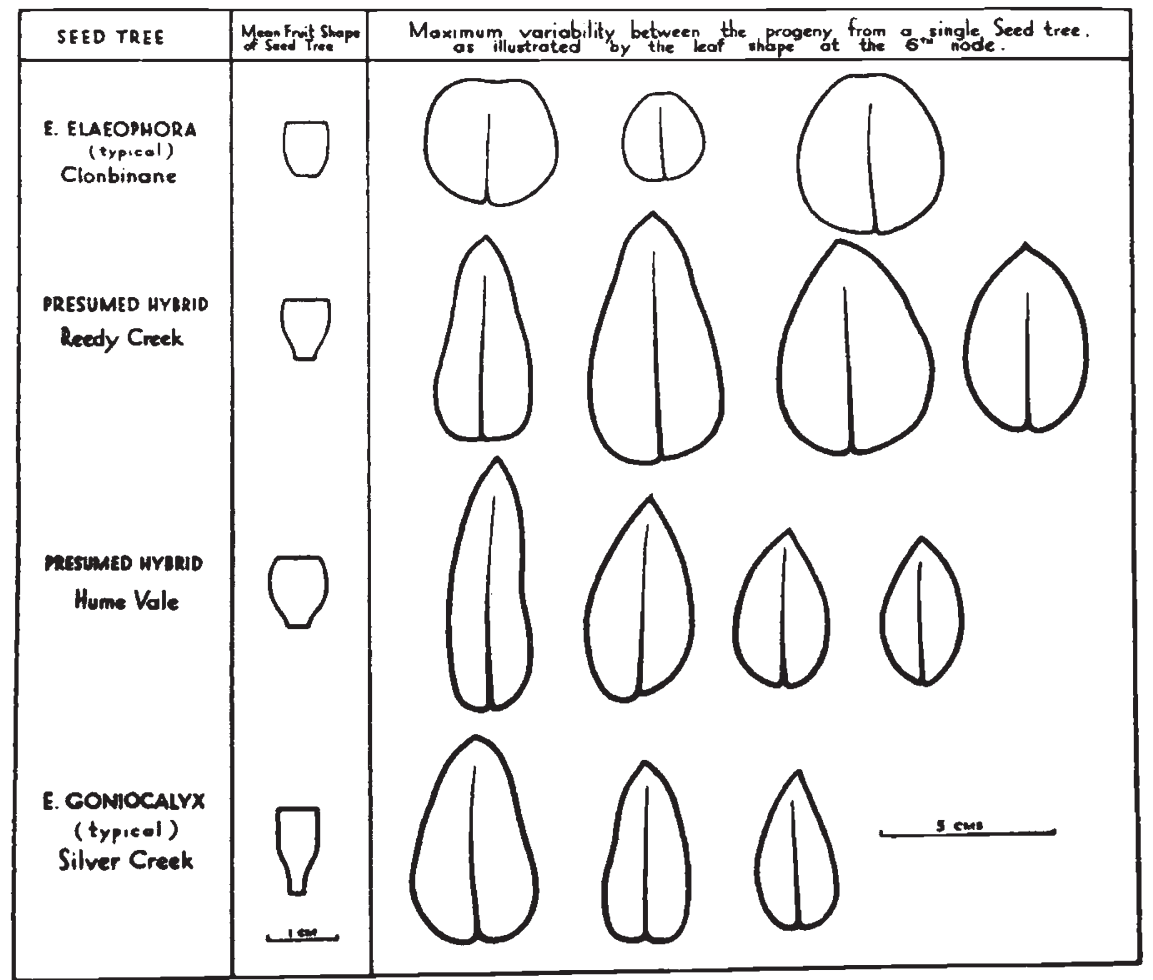

FIG. 4.-The variability between seedlings from the same parent, as illustrated by the leaf shape at the sixth node.

evenly spaced. No other conscious selection was practised except to remove any very stunted or diseased plants. The seedlings were finally harvested when they showed 6-8 pairs of fully expanded leaves. Altogether the progeny of fourteen trees were raised.

An examination of the seedlings grown indicated that there was less variability between those raised from parents typical of either $E$. elaeophora or $E$. goniocalyx, than between those from parents with an appearance intermediate between those species. This is illustrated in fig. 4, where leaves from the 6th node of four different seedlings 
from each of several parents, have been drawn. The leaves were chosen to show the maximum variability between the progeny raised from each parent.

If the seedlings from parents typical of each of the three groups studied were pooled and the variance of the length-breadth ratio of the leaves calculated, it was greater for the progeny of "intermediate" trees than for those from either E. elaeophora or E. goniocalyx at 5 of the 6 nodes measured. This is shown in table $I$, from which it is evident that at the later nodes the variability of the progeny of the intermediate trees is maintained whereas the progeny of each of $E$. elaeophora and $E$. goniocalyx tend to become more uniform.

TABLE 1

The relative variability of the length-breadth ratio of seedling leaves of progeny from trees typical of E. elaeophora, E. goniocalyx and trees intermediate between them

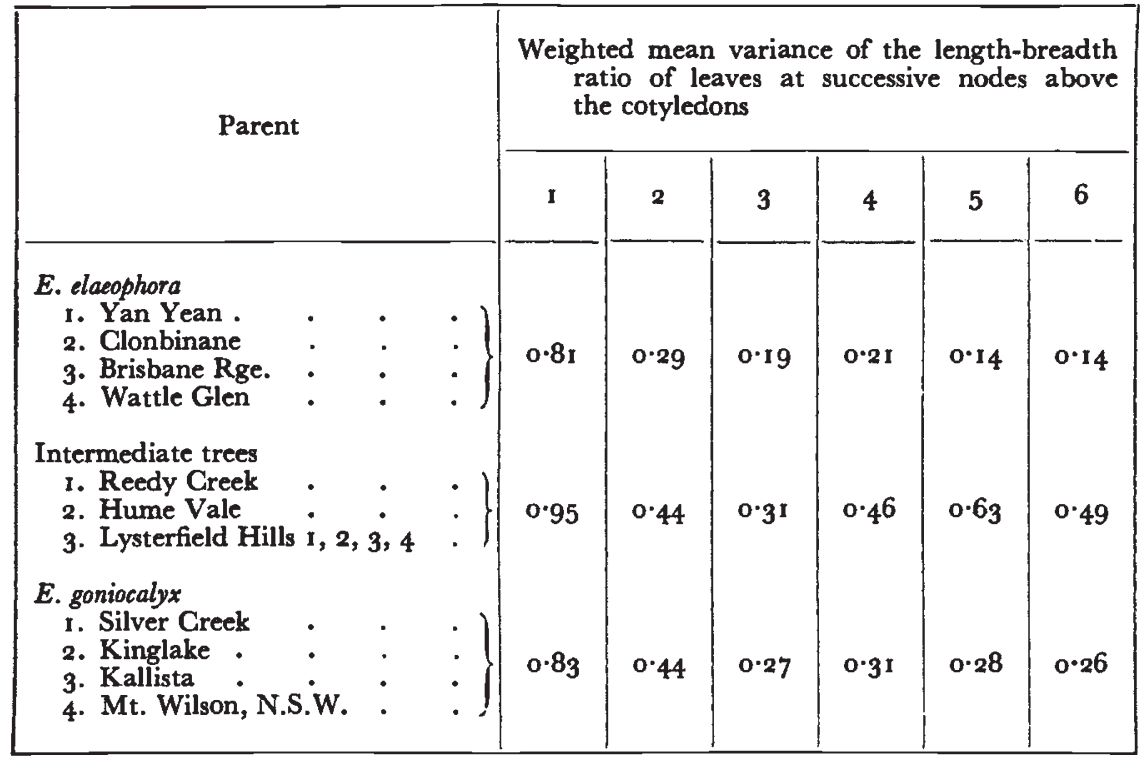

The analysis of the variability in a population containing species and presumed hybrids may be carried further as follows. Consider the inheritance in pure lines and hybrids, of a character controlled by 4 genes. Assume that the parents $\left(P_{1}\right.$ and $\left.P_{2}\right)$ are each homozygous for different alleles; that the viability and number of gametes produced by each is similar; that the $F_{1}$ hybrid between them is fully fertile ; that the influence of the environment is negligible and that the overall mode of action of the genes is additive on a suitable scale. The mean measurements and their variances for the character in the parents and hybrid derivatives are shown in table 2.

When plotted graphically these values outline a triangle (fig. 5), where dimensions will depend upon the character measured. Linkage 
TABLE 2

The mean measurement and its variance of a character controlled by four genes whose effects are additive

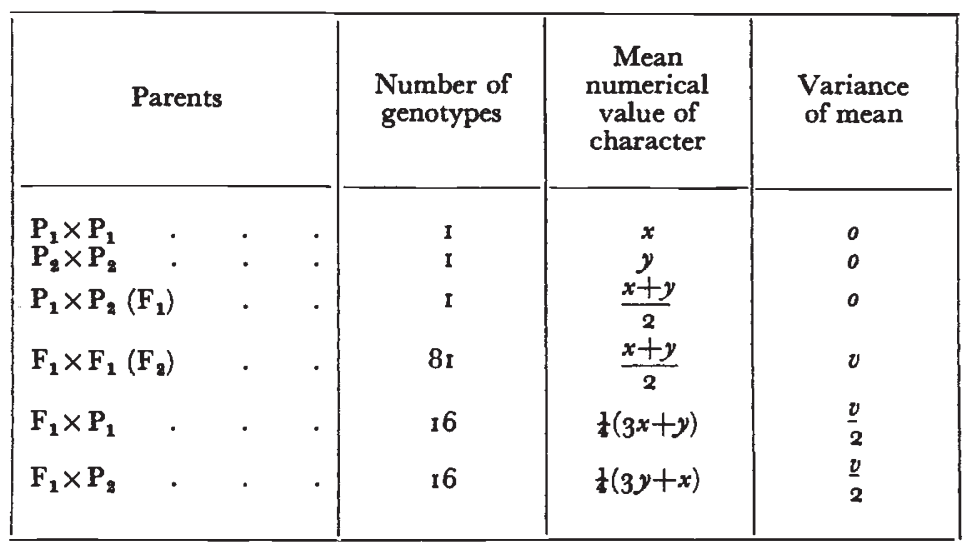

does not alter the triangular shape nor do other parental combinations such as an $F_{1}$ crossed with an $F_{2}$ segregate, or an $F_{1} 90$ per cent. selfed and ro per cent. outbred, all have mean-values and variances which fall within the triangle. Such a situation might arise in a population undergoing active introgression.

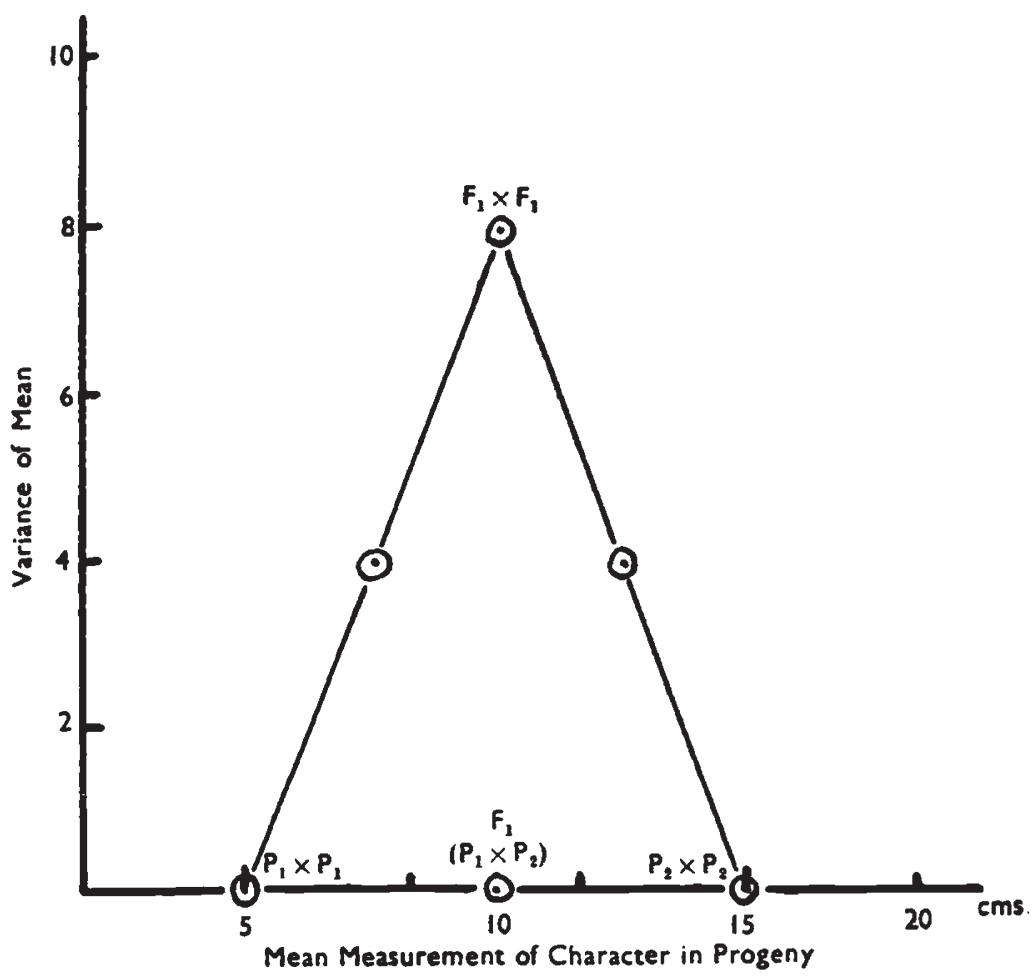

Fic. 5.-The theoretical distribution of the means and variances for a character measured on the families whose parents are given. 
This theoretical hypothesis can be tested with the progeny of selfings and hybrids of species, varieties and so on, if they yield fertile hybrids, for it can be assumed for most of these that they differ principally in possessing different allelic genes. Suitable data is provided by East (1950) for cob length in maize. His numerical values are shown in table 3 and are graphed in fig. 6, from which it is seen, that for the progeny whose parents are indicated in the table, the mean and its variance for cob length mark out a triangular area.

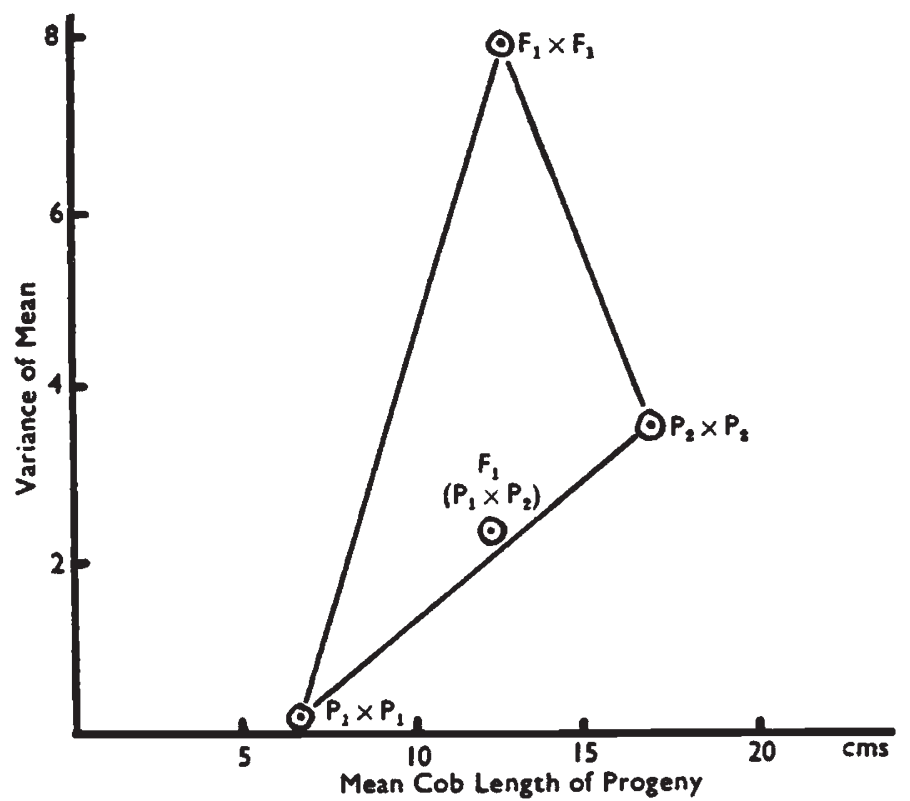

Fic. 6. - The distribution of the means and variances for cob length in maize measured on the families whose parents are given.

The application of this method of presenting data may be illustrated with the results for $E$. elaeophora and $E$. goniocalyx. When the mean

TABLE 3

The mean and its variance for cob length in the parents and two hybrid generations of maize

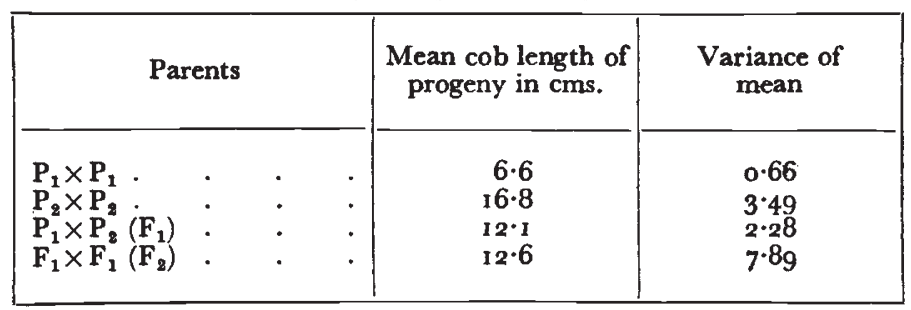

length-breadth ratios of the leaves from seedlings raised from each tree studied are plotted against their variances, the co-ordinates were included within a triangle. This is shown in fig. 7 which is based upon the data of table 4 . 


\begin{tabular}{|c|c|c|c|c|c|}
\hline \multirow{8}{*}{ 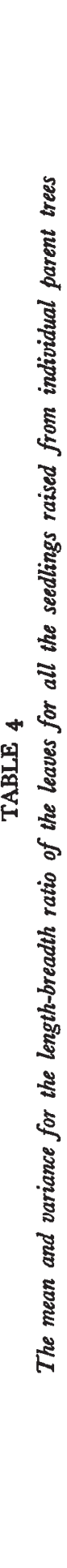 } & \multirow{6}{*}{ 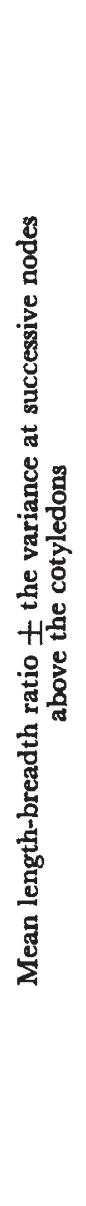 } & $\infty$ & 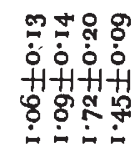 & 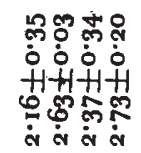 & 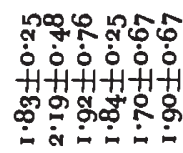 \\
\hline & & n & 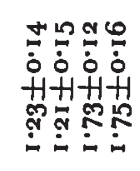 & 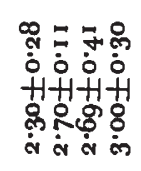 & 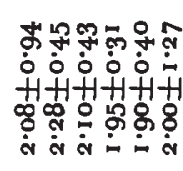 \\
\hline & & $\sigma$ & 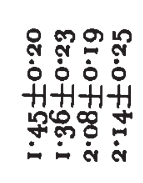 & 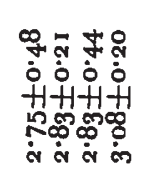 & 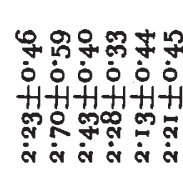 \\
\hline & & or & 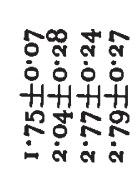 & 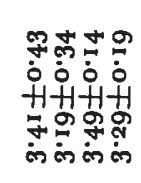 & 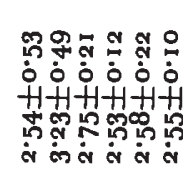 \\
\hline & & N & 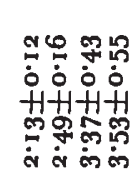 & 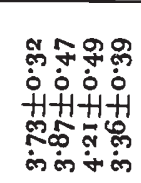 & 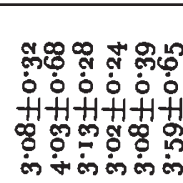 \\
\hline & & m & 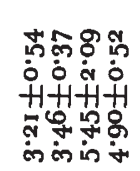 & 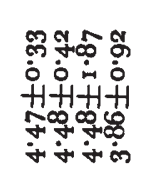 & 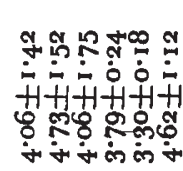 \\
\hline & \multicolumn{2}{|c|}{ 苞 } & 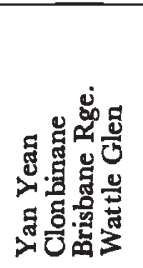 & 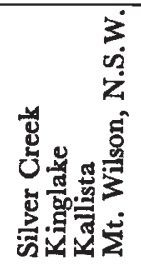 & 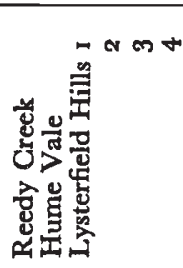 \\
\hline & \multicolumn{2}{|c|}{ 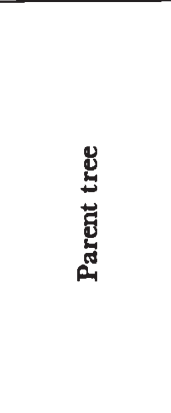 } & 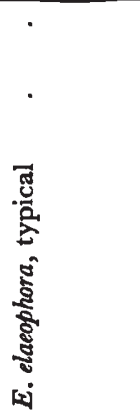 & 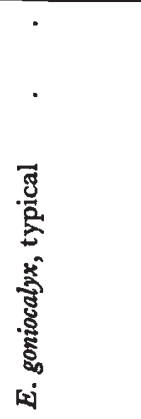 & 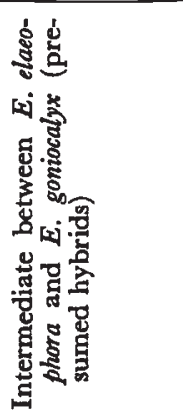 \\
\hline
\end{tabular}


The co-ordinates within this triangle are distributed in such a way that the progeny of trees acceptable as $E$. elaeophora or $E$. goniocalyx tend to occur at the basal angles and those from the "intermediate" trees tend to occupy the centre and apex of the triangle. Such a distribution of means and variances would be expected if the "intermediate" trees were hybrid derivatives of $E$. elaeophora and $E$. goniocalyx.

When the mean-variance diagrams are compared at successive nodes it is observed that the parental trees are not similarly disposed in each ; but an analysis of the causes of this variability would be

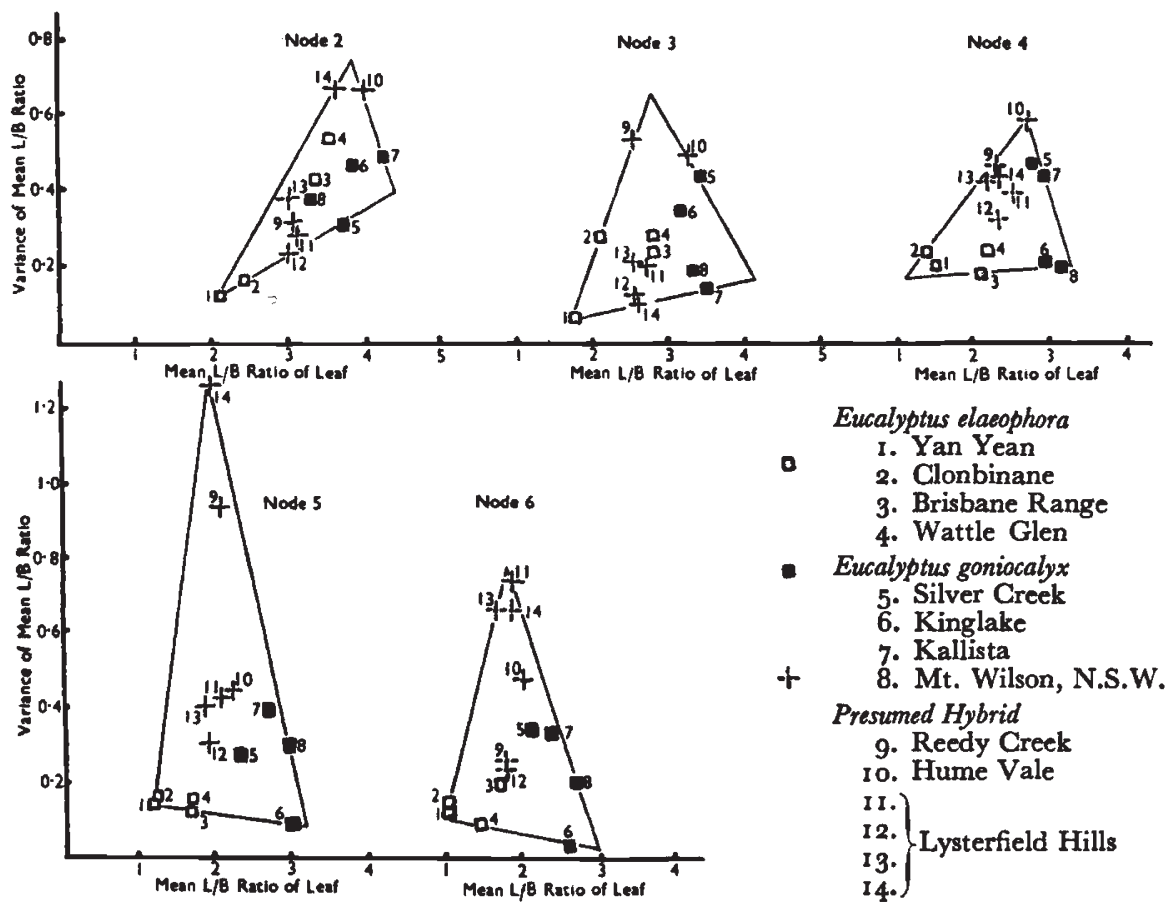

Fig. 7.-The distribution of the means and variances for the length-breadth ratios of seedling leaves in families from several Eucalyptus trees whose taxonomy is indicated. The data for the first node above the cotyledons are omitted as they do not conform to the general pattern.

difficult, and is better postponed until more data are available, and direct proof obtained that hybridisation is occurring in accordance with the premises underlying the theory.

\section{DISCUSSION}

Both the general appearance of the "intermediate" trees and their occurrence along the boundary where the habitats of $E$. elaeophora and $E$. goniocalyx meet, suggest that they might be hybrid derivatives of those species. The flowering seasons of the two species are concurrent from about February to June, so opportunity for hybridisation would exist. Furthermore, the progeny of the trees intermediate 
between $E$. elaeophora and $E$. goniocalyx show segregation of characters towards these species, if leaf shape is considered (fig. 4). From the variety of leaf shapes obtained at comparable nodes of seedlings from each "intermediate" parent, it would appear that many genes control this character.

That the two species concerned can interbreed has been established with reasonable certainty from the progeny studies. No simple ratios for different leaf shape have been obtained and nothing is known concerning the extent of inbreeding under natural conditions. It is suggested, however, that the application of the "triangle" method illustrated above supplies confirmation for the hybrid origin of the "intermediate" trees and might be used to analyse other hybrid populations.

\section{SUMMARY}

I. Several stands of trees with characters intermediate between $E$. elaeophora and $\boldsymbol{E}$. goniocalyx have been studied.

2. Segregation of characters amongst the seedlings from individual " intermediate" trees suggested that they were of hybrid origin.

3. Further support for this interpretation was afforded by field studies, which showed that "intermediate" trees occurred only in localities where $E$. elaeophora and $E$. goniocalyx grew nearby.

4. The means and variances of the length-breadth ratios of the seedling leaves for the progeny of selected trees have been used to illustrate a possible method of determining the parentage of hybrid swarms.

Acknowledgments. - The writer has pleasure in thanking Professor J. S. Turner of the Botany School, Melbourne University for his help and encouragement during the course of this work, and Miss N. Mirams of the University Department of Visual Aids for assistance in preparing the diagrams.

\section{REFERENCES}

ANDERson, E. A. 1949. Introgressive Hybridisation. John Wiley \& Sons.

BAKER, R. T., AND SMTTH, H. G. 1920. A Research on the Eucalpyts especially in regard to their Essential Oils. 2nd Ed. Govt. Print., Sydney.

BENTHAM, G. 1866. Flora Australiensis, 3, 229. Lovell Reeve and Co.

BRETT, R. G. 1938. A survey of the Eucalyptus species in Tasmania. Papers and P.R.S. Tas., 1937, 75.

CARTER, C. E. 1945. The Distribution of the more important Timber Trees of the Genus Eucalyptus. Commonwealth Forestry Bureau. Atlas No. I.

CLIFFORD, H. T. 1953. On the distribution of the species of Eucalyptus in the region of the Dandenong Range, Victoria. P.R.S. Vic., 65,30 .

EAST, E. M. 1950. As quoted in Principles of Genetics by E. W. Sinnott et al., $195^{\circ}$. McGraw Hill Book Coy.

EWART, A. J. 1930. Flora of Victoria. Melbourne University Press.

maiden, J: H. 1914. A Critical Review of the Genus Eucalyptus, 2, 267. Govt. Print., Sydney.

PRYOR, L. D. 1950. A hybrid Eucalyptus. Proc. Linn. Soc., N.S.W., 75, 96. 